\title{
Interpretação, silêncio, ensino
}

Sheila Elias de Oliveiral

Résumé: Fondé sur la conception de silence d'Eni Orlandi, cet article analyse la relation entre dits et non-dits dans l'énonciation d'un manuel d'éthique en gynécologie et obstétrique. L'auteur préconise la pertinence des dispositifs d'interprétation qui prennent en compte cette relation dans la formation critique des sujets et attire l'attention sur le fait qu'en temps de menace à la démocratie cette conception de silence permet de comprendre le travail des sens dans le fonctionnement de l'implicite, de l'anti-implicite et de la censure.

Mots-clés: silence; censure; implicite; liberté.

Resumo: Tendo como base a concepção de silêncio de Eni Orlandi, este artigo analisa a relação entre ditos e não-ditos na enunciação de um manual de ética em ginecologia e obstetrícia. A autora defende a pertinência de dispositivos de interpretação que levem em conta essa relação na formação crítica dos sujeitos e chama a atenção para o fato de que em tempos de ameaça à democracia essa concepção de silêncio permite compreender o trabalho dos sentidos no funcionamento dos implícitos, anti-implícitos e da censura.

Palavras-chave: silêncio; censura; implícito; liberdade.

A liberdade, que é uma conquista, e não uma doação, exige uma permanente busca. Busca permanente que só existe no ato responsável de quem a faz. Ninguém tem liberdade para ser livre: pelo contrário, luta por ela precisamente porque não a tem.

Não é também a liberdade um ponto ideal, fora dos homens, ao qual inclusive eles se alienam. Não é idéia que se faça mito.

É condição indispensável ao movimento de busca em que estão inscritos os homens como seres inconclusos.

Paulo Freire, em Pedagogia do oprimido, 1970.

\section{Silêncio e interpretação}

Há épocas em que alguns conceitos produzidos no interior das Ciências Humanas se tornam ainda mais pertinentes diante de fatos sociais que chamam à reflexão teórica. É o que hoje acontece com a concepção de silêncio formulada por Orlandi em 1992². Apresentarei aqui a análise de uma enunciação sobre a relação médico-paciente em um manual de ética médica para ginecologia e obstetrícia. Levarei em conta tanto o que a enunciação médica diz quanto o que não diz, não só em seus implícitos, mas também em seus silên-

1 Professora do Departamento de Linguística do Instituto de Estudos da Linguagem da Unicamp.

2 A concepção de silêncio é desenvolvida em As formas do silêncio no movimento dos sentidos (1992). O livro recebeu o prêmio Jabuti em Ciências Humanas em 1993. 


\section{Conexão Letras}

cios. Com essa análise, quero destacar a importância de dispositivos de interpretação que instrumentalizem os sujeitos para compreender a relação entre ditos e não-ditos constitutiva dos sentidos em toda enunciação. Tanto mais em tempos de ameaça à democracia como o que estamos vivendo.

Orlandi (1992, p. 160) afirma que "para compreender um discurso, devemos perguntar sistematicamente o que ele cala”. Perguntarei aqui o que cala a relação implícita entre respeito à intimidade da paciente e pudor em um manual de ética médica. Trabalharei sobre a política do silêncio, que "produz um recorte entre o que se diz e o que não se diz" (ORLANDI, 1992, p. 75). De um lado, o silêncio constitutivo permite observar aquilo a que o dizer não remete por uma ausência necessária, funcionando como um anti-implícito. De outro lado, o silêncio local, que diz respeito à interdição ao dizer, permite observar gestos de censura.

\section{Do implícito ao silêncio}

As semânticas linguísticas têm lidado desde o século XIX com a relação entre sentidos explícitos e sentidos implícitos. No domínio da enunciação, essa relação é trabalhada no movimento entre as possibilidades que a língua oferece e o dizer dos falantes. É nessa direção que Oswald Ducrot se dedica, nas décadas de 1960 e 1970, à distinção entre sentidos postos, pressupostos e subentendidos. Ducrot dá visibilidade aos diferentes efeitos de responsabilização dos interlocutores pelo dizer inscrito nessas três formas de significar e mostra que os subentendidos produzidos na enunciação podem gerar pressupostos na língua. Assim, ele torna visível a impossibilidade para o semanticista de pensar a língua fora da relação com a linguagem.

Se Ducrot lança luz sobre o que ele chama de caráter polêmico da língua, isto é, o fato de que "ela se apresenta, fundamentalmente, como o lugar do debate e da confrontação de subjetividades" (DUCROT, 1969, p. 30), ele não coloca como questão do semanticista a compreensão da natureza e do funcionamento dessas "subjetividades" na relação com a linguagem, ainda que, forçosamente, sua teorização produza um conjunto de implícitos sobre elas. Esse ponto cego na reflexão de Ducrot está na base da crítica de Paul Henry (1977). Henry reivindica a compreensão do falante como sujeito constituído na relação entre inconsciente e Ideologia, pela qual a linguagem pode ser tomada em sua não-transparência na relação com a exterioridade ideológica.

A discussão sobre o tratamento do sentido nas semânticas linguísticas realizada pela Análise do Discurso na França é trazida para o Instituto de Estudos da Linguagem da Unicamp por Eni Orlandi, que a amplia em um caminho de reflexão próprio, tocado pela historicidade das línguas e da produção de conhecimento sobre a linguagem no Brasil. A semântica discursiva desenvolvida pela autora afeta de maneira decisiva a reflexão sobre a enunciação produzida por Eduardo Guimarães, que estabelece um diálogo entre as semânticas da enunciação e a teoria não-subjetiva da subjetividade sendo desenvolvida pela AD no interior do materialismo histórico.

Orlandi, ao pensar o silêncio como "a própria condição da produção de sentido" (ORLANDI, 1992, p. 70), como "um lugar de recuo necessário para que se possa significar, para que o sentido faça sentido" (ORLANDI, 1992, p. 13), traz uma nova compreensão para a relação entre o dito e o não-dito. O não-dito não se restringe ao que é implicitado no dizer e o implícito é tomado como o resto visível, "subproduto do trabalho do silêncio" na significação. O que está dito, o que está posto no dizer tem sua "explicitude" interro- 
gada, já que as palavras "são atravessadas de silêncio; elas produzem silêncio; o silêncio fala por elas; elas silenciam" (ORLANDI, 1992, p. 14). É preciso, então, para compreender os sentidos em uma enunciação, considerar o que ela silencia.

Essa compreensão dá uma nova dimensão à questão ética indicada por Ducrot ao tratar dos efeitos de responsabilização pelo dizer na relação entre dito (atribuído ao eu), pressuposto (partilhado pelo eu e pelo tu) e subentendido (atribuído ao $t u$ ). O não-dito significa por sua ausência no que é dito; assim, para além dos efeitos de responsabilização, o eu que fala está implicado tanto no dito quanto no não-dito, que atravessa de maneira constitutiva - pela relação com o inconsciente e a Ideologia - sua enunciação.

A análise que farei a seguir parte da interrogação do sentido de respeito à intimidade da paciente na enunciação dos Cadernos de Ética em Ginecologia e Obstetrícia produzidos pelo Conselho Regional de Medicina do Estado de São Paulo (CREMESP) em 2011. Essa enunciação do CREMESP toma como base o código federal de ética médica, que afirma ser vedado ao médico "desrespeitar o pudor de qualquer pessoa sob seus cuidados profissionais". A relação implícita entre os dois dizeres permitirá percorrer, na enunciação dos Cadernos CREMESP, ecos da palavra pudor tal como ela foi empregada na construção do campo da saúde da mulher no século XIX. É então por pudor que iniciamos a reflexão.

\section{Pudor na língua portuguesa}

Para compreender os sentidos de pudor na história da medicina, e os ecos de seus sentidos na enunciação de respeito à intimidade da paciente nos Cadernos CREMESP, percorro alguns dicionários de língua portuguesa. Observar nos verbetes lexicográficos o que eles apresentam como usos gerais da palavra permitirá compreender a relação entre o dizer médico e o dizer do senso comum, tal como este é registrado nos dicionários. Tomo quatro obras, as duas primeiras produzidas em Portugal no século XVIII; as duas últimas, publicadas no Brasil no século XXI. São elas: o Vocabulário Português e Latino de Rafael Bluteau, na segunda edição, de 1728; o primeiro dicionário monolíngue do português, o Dicionário da Língua Portuguesa de Antonio de Morais Silva, em sua primeira edição, de 1789, inspirada no Vocabulário de Bluteau; o Grande Dicionário Houaiss, de 2009, na versão on-line; e o Michaelis Dicionário Brasileiro da Língua Portuguesa, s/d, também em edição on-line, não datada, com copyright de $2018^{3}$.

1. Vocabulário Português e Latino, Raphael Bluteau. 1728, 2ed.

Pudor. Honestidade, modéstia, honesta vergonha. Pudor, oris. Masc. Cic. (O culto das mulheres está no Pudor. Lacerda. Paneg. do Marq. de Mar. pág.15) Disponível em: <http://www.brasiliana.usp.br/handle/1918/002994-06\#page/832/mode/1up>. Acesso em: 20 nov. 2016.

3 Os dois primeiros dicionários são publicados em Portugal e representam a língua descrita como língua de Portugal e das suas colônias. O Brasil é, entre as colônias, a que tem lugar de destaque na descrição lexicográfica da língua. Mesmo em Bluteau, um dicionário português-latim, encontramos entradas como 'banana' sem nenhuma remissão à língua latina e explicada segundo seu uso no Brasil. Morais Silva, não podemos esquecer, é brasileiro. Quanto aos dicionários contemporâneos, o de Antonio Houaiss, elaborado no Brasil, que teve a primeira edição em 2001, representa a língua descrita como aquela de todos os povos que falam o português; já o Michaelis, trazido para o Brasil em 1950, apresenta a língua descrita hoje, na edição on-line, não datada, como 'português do Brasil'. Podemos assumir que pudor, ligada a instituições trazidas para o Brasil, notadamente a Igreja, guarde, em seu funcionamento enunciativo no país, relação com a memória lusitana, que se confunde, em nossos dicionários com a memória brasileira da palavra. 
Culto. Ornato. Propriamente se diz de tudo com que as mulheres ornam o corpo. Cultus foeminus. Caes. Floro no livro 4.cap.II diz Cleopatra máximos cultus induta, \& Petronio Et tot nova nomina cultus.

Tratava pouco do culto de sua pessoa. Cultus modicus erat. Tacit. O Culto das mulheres está no pudor, não no vestido. Paneg. do Marq. de Mar pág. 15. Além de tratar pouco do Culto de sua pessoa. Lob. Cort. Na Ald. Pág. 22.4 .

Disponível em: <http://dicionarios.bbm.usp.br/pt-br/dicionario/1/culto $>$. Acesso em: 20 nov. 2016.

2. Dicionário da Língua Portuguesa, A. de Morais Silva, 1789.

PUDOR, s.m. Honestidade; modéstia, honesta vergonha. Barros. Vic. Verg. f. 294. Pudor é das coisas torpemente feitas. O culto das mulheres está no pudor.

Disponível em: <http://dicionarios.bbm.usp.br/pt-br/dicionario/2/pudor $>$. Acesso em: 20 nov. 2016.

3. Michaelis Dicionário Brasileiro da Língua Portuguesa, s/d, copyright Ed. Melhoramentos, 2018.

\section{Pudor pu·dor sm}

1 Sentimento de timidez ou vergonha, produzido por algo que possa ferir os padrões morais e/ou éticos: "Na minha infância, todos os nus estavam vestidos. Bem me lembro dos dominós, das caveiras, dos pierrots. O pudor não fazia concessão" (NR). 2 Sentimento de recato relacionado à área da sexualidade; pudicícia: Entregou-se ao homem amado, sem pudor. Antôn: cinismo. ETIMOLOGIA lat pudor.

Disponível em: $<\mathrm{http}: / /$ michaelis.uol.com.br/busca?r=0\&f=0\&t=0\&palavra=pudor $>$. Acesso em: 02 maio 2018.

4. Grande Dicionário Houaiss, 2009, edição on-line.

PUDOR (1540 cf. JBarV) substantivo masculino 1 sentimento de vergonha, timidez, mal-estar, causado por qualquer coisa capaz de ferir a decência, a modéstia, a inocência 2 sentimento e atitude desenvolvidos por uma educação rígida calcada em conceitos culturais, ger. de base religiosa, que impedem que certas partes do corpo sejam expostas com naturalidade, sem constrangimento [A amplitude e a distribuição dessas partes variam de acordo com as culturas.] 3 vergonha, constrangimento, de base ger. cultural, para falar a respeito ou praticar determinados atos ligados à área da sexualidade, das funções fisiológicas, dos sentimentos íntimos, da afetividade etc.; recato, decência, pudicícia, pundonor 〈atentado ao p.) 4 sentimento de vergonha com respeito a atos que ferem as qualidades de caráter de um indivíduo, como a decência, a honestidade, a honra etc.; pejo ‘ficou rubro de p. quando suspeitaram da sua honestidade> Sinônimos: ver antonímia de indecência. Antônimos: cinismo; ver tb. sinonímia de indecência. Lat. püdor,ōris no sentido de 'vergonha, pejo'; ver pud-

Disponível em: <https://houaiss.uol.com.br/pub/apps/www/v3-3/html/index.php\#1>. Acesso em: 02 maio 2018. 
“O culto das mulheres está no pudor, não no vestido". Este enunciado que encontramos em 1728 no Bluteau é retomado por Morais em 1789. O “culto”, ensina Bluteau, é o "ornato" do corpo da mulher. A valoração positiva do pudor se filia a um discurso estético-moral pelo qual se exerce o controle do corpo da mulher, de seus modos de expressão, de suas condutas. No Morais, os sinônimos reforçam esse direcionamento: pudor é "honestidade, modéstia, honesta vergonha". Quase três séculos depois, a "vergonha" que a mulher deve ter do corpo, em vista de sua "honestidade", ressoa no sentido de pudor no Michaelis. Nesse dicionário, nenhuma das duas definições é direcionada para o feminino; no entanto, o exemplo da segunda definição, que toca à sexualidade, remete à mulher. A definição - "sentimento de recato relacionado à área da sexualidade; pudicícia" é seguida do exemplo: "Entregou-se ao homem amado, sem pudor". O controle do pudor pelo homem está indicado: a mulher pode abrir mão do pudor na "entrega ao homem amado" homem este a quem nenhum pudor é atribuído. Reforçando o sentido moral e a valoração positiva, o Michaelis apresenta cinismo como antônimo de pudor.

O Houaiss não liga pudor diretamente ao feminino. Ele ainda se diferencia dos anteriores por apresentar, entre as definições, uma que significa o pudor como uma construção cultural, valorando-o negativamente: "sentimento e atitude desenvolvidos por uma educação rígida calcada em conceitos culturais, ger. de base religiosa, que impedem que certas partes do corpo sejam expostas com naturalidade, sem constrangimento [A amplitude e a distribuição dessas partes variam de acordo com as culturas.]". Nessa definição, pudor se opõe a naturalidade e se liga a constrangimento. Essa valoração negativa do pudor se opõe aos sentidos postos nas outras definições: Pudor é "sentimento de vergonha, timidez, mal-estar, causado por qualquer coisa capaz de ferir a decência, a modéstia, a inocência"; é "recato, decência, pudicícia, pundonor"; diz respeito a "atos que ferem as qualidades de caráter de um indivíduo, como a decência, a honestidade, a honra". $\mathrm{O}$ antônimo cinismo, já presente no Michaelis, se repete, ao lado de indecência.

No dizer dos dicionários, pudor demarca uma linha de comportamento e sentimento. O percurso lexicográfico pela história da palavra nos mostra um direcionamento comportamental que diz respeito à sexualidade, e vai além dela. $\mathrm{O}$ discurso moral que aí significa trabalha sobre a divisão de gêneros, atribuindo à mulher, de modo positivo, o cultivo do pudor. A palavra não significa apenas a contenção da sexualidade feminina, mas, de modo mais amplo, a contenção da subjetividade feminina, marcada na relação com o corpo: a mulher deve "vestir" o pudor. A voz dissonante do Houaiss é minoritária; ainda assim, ela indica um movimento polissêmico na divisão da palavra, pelo qual pudor não é remetida explicitamente à mulher e é situada historicamente como parte de um mecanismo cultural de controle do corpo.

A medicina da mulher faz eco ao discurso moral dominante nos dicionários, ao mobilizar a palavra pudor como critério para definir os procedimentos do exame médico. É desse movimento da palavra que passo a tratar.

\section{Pudor em enunciações da "medicina da mulher"}

\section{Inícios da ginecologia e da obstetrícia}

Ao refletir sobre o conhecimento que a "medicina da mulher" produz, Rohden afirma que ele é "elaborado a partir da percepção de como elas [as mulheres] são distintas em relação aos homens. Não há, porém, uma ciência do homem tendo como ponto de partida a sua diferença da mulher" (ROHDEN, 2002, p. 122). A existência da "saúde da 
mulher" ou "medicina da mulher" sem contraposição a uma "medicina do homem" instituída como área médica aponta, portanto, para uma disparidade no olhar médico sobre o corpo humano.

A ginecologia e a obstetrícia se estabelecem como áreas médicas no Ocidente no século XIX. Disputas de saberes sob a égide da Igreja antecedem seu estabelecimento: uma delas, a disputa entre parteiras e cirurgiões, diz respeito, de um lado, à oposição entre o saber fruto da experiência e o saber fruto da especulação; de outro, aos direitos de acesso ao corpo da mulher. Outra disputa, entre cirurgiões e médicos, também diz respeito aos direitos de acesso ao corpo do outro, seja ele homem ou mulher. Ela surge da separação dessas categorias na Reforma Gregoriana (século XII), quando os médicos, dedicados à vida monástica, ficam restritos à especulação e aos livros, uma vez que o contato com os corpos alheios é permitido somente aos leigos.

Segundo Rohden, os cirurgiões criticam técnica e moralmente as parteiras, mas não são bem aceitos pela Igreja para tratar das mulheres sob o argumento de que, sendo homens, ferem o "pudor feminino". À medida que o poder da Igreja diminui, as ciências têm mais autonomia. Nos séculos XVII e XVIII, ao desenvolver instrumentos e técnicas que se tornam conhecidos na França e na Inglaterra, os cirurgiões ganham prestígio e reconhecimento em relação às parteiras. No século XIX, tendo como ponta de lança os Estados Unidos, a França e a Inglaterra, a obstetrícia e a ginecologia se desenvolvem, esta última estudando e tratando o aparelho reprodutivo e as doenças femininas. "Pouco a pouco a ginecologia se desenvolve mais próxima da cirurgia. (...) Em função de seu conhecimento e experiência particular do corpo feminino, eram muitas vezes os obstetras que se tornavam ginecologistas" (ROHDEN, 2001, p. 62).

No Brasil, quando essas especialidades iniciam, elas buscam na Europa a referência para o saber clínico. Essa relação nos autoriza a tomar a enunciação da medicina europeia no século XIX como constitutiva da memória de sentidos da medicina brasileira. Partirei da palavra pudeur, cognata de pudor, para mostrar sua importância na definição de procedimentos para o exame clínico do corpo da mulher na medicina francesa.

Segundo Courtine e Vigarello, a palavra pudeur surge entre os séculos XV e XVI. Eles afirmam que "à aparição da palavra corresponde a ascensão do sentimento" e que "a ascensão do sentimento de pudor no campo das práticas civis durante os séculos XVI e XVII faz parte de uma educação do olhar sobre o corpo" (COURTINE e VIGARELLO, 1987, p. 79). No português, segundo o Grande Dicionário Houaiss (2009), pudor é atestada pela primeira vez no Diálogo da Viciosa Vergonha, de João de Barros publicado em 1540 ao lado de sua Gramática da Língua Portuguesa. O Diálogo, que se dá entre pai e filho, visa à formação moral dos jovens. Tanto na França como no Brasil, pudeur e pudor significam um controle do corpo. Na discussão médica na França do século XIX, de modo semelhante ao que vimos nos dicionários de língua portuguesa do século XVIII, esse controle é direcionado para o corpo da mulher.

\section{'Pudeur' na enunciação de médicos franceses do século XIX}

A relação entre pudor feminino e prática médica no século XIX é tematizada em um artigo de 2004 publicado no boletim francês de História das Ciências Médicas, que propõe apresentar "as dificuldades que os médicos, no século XIX, afirmam ter encontrado para examinar os órgãos genitais das mulheres" e suas propostas "para persuadir as mulheres a se deixar examinar, insistindo sobre as ações que eles recomendam colocar em 
prática para não alarmar nem ferir o pudor delas". Segundo a autora, "o pudor da mulher era o responsável [pelas dificuldades dos médicos] na maioria dos casos" (Arnaud-Lesot, 2004, p. 207, tradução e grifos meus).

A autora, Arnaud-Lesot, assume para si o discurso médico, e toma o pudor como um fato feminino, uma qualidade própria da mulher. Em um gesto de distanciamento analítico do discurso médico, proponho retomar no texto da autora a enunciação de alguns médicos, para mostrar que a palavra pudeur (pudor), ao ser mobilizada, faz operar todo um imaginário sobre a mulher que silencia a relação com o corpo masculino, tanto do paciente-homem quanto do médico, significando as alegadas dificuldades de exploração clínica do corpo feminino como oriundas do ser mulher.

Segundo Arnaud-Lesot, alguns médicos apontam fatores diversos para a "resistência feminina" ao exame clínico: o medo de dor no exame, do diagnóstico e do tratamento; o receio de questionamentos acerca da sua sexualidade; ou ainda a ignorância de que sintomas não aparentemente relacionados à genitália podem estar ligados a ela. Contudo, segundo ela, "numerosos são aqueles, enfim, para os quais o pudor feminino dá conta das dificuldades que eles confrontam para examinar as mulheres". Ela cita o médico J. Vigarous: "Para J. Vigarous [1801], ele é mesmo, sem contestação, "a dificuldade mais essencial que tiveram que vencer os médicos de todos os tempos na pesquisa das doenças do sexo". É ele que impede as mulheres de consultar o médico. É ele que as faz recusar se deixar examinar" (Arnaud-Lesot, 2004, p. 208, tradução e grifo meu).

A historiadora afirma que, diante desse quadro, o médico deve proceder de modo que "o pudor da mulher não seja nem alarmado, nem ferido". Uma vez que a paciente é convencida a se submeter ao exame, algumas condutas são sugeridas:

São numerosos os que recomendam, assim, só praticar o exame dos órgãos genitais quando indispensável, abreviar tanto quanto possivel sua duração, não multiplicar os exames, escolher o menos árduo para a paciente quando se abrem diferentes possibilidades, e não pedir ajuda a outros, cuja presença é frequentemente mal tolerada. Aconselha-se, para o toque vaginal, não tatear, não fazê-lo imediatamente no início da consulta, e estar atento para não tocar o clitóris e o ânus durante a prática.

Mas a principal precaução é não descobrir a mulher. (...) Essa regra é enunciada durante todo o século XIX para a prática do toque vaginal. O pudor e a decência, não permitindo ao médico olhar os órgãos genitais externos da mulher que ele examina, a impõem. (...) "Salvo os casos em que a intervenção do espéculo é indispensável, a exploração do útero, da vulva e da vagina pode e deve se fazer apenas com o dedo, dito de outro modo, pelo toque. $\mathrm{O}$ toque (...) tem a vantagem de simplificar as coisas, de administrar o pudor da mulher, de evitar o dissabor de estar descoberta, de expor suas partes genitais aos olhares", explica E. Gibout [1886]. (Arnaud-Lesot, 2004, p. 210, tradução e grifo meus).

Uma ciência experimental como a medicina define seus procedimentos de observação clínica em função de um fator moral, exterior à ciência, que ela atribui à mulher e não reconhece como tabu social partilhado pelo médico em relação ao corpo e à sexualidade. A força do tabu é tal que as restrições na observação clínica são recomendadas mesmo em se admitindo que "doenças importantes a conhecer possam assim escapar ao médico" (Arnaud-Lesot, 2004, p. 210). Na enunciação de um dos médicos citados por Arnaud -Lesot, M. Colombat [1843], fica claro que o tabu não está apenas na mulher. O pudor é valorizado pelo médico como atributo das "mulheres honestas": "ainda que a aplicação do espéculo exija sempre, ao menos para as mulheres honestas, um grande sacrifício 
do seu pudor, esta consideração não deverá nunca parar o médico quando ele suspeitar de uma lesão grave ou passível de se tornar grave" (apud Arnaud-Lesot, 2004, p. 212, tradução e grifo meus).

Encontramos, na enunciação contemporânea da medicina da mulher, ecos desse modo de significar o pudor na relação médico-paciente, que não leva em conta as questões do médico como sujeito inscrito em um conjunto de práticas sociais que vão além da medicina. É o que vamos acompanhar no manual do CREMESP.

\section{‘Pudor' na ética médica no Brasil contemporâneo}

$\mathrm{O}$ código de ética médica está em revisão neste momento no Brasil. $\mathrm{O}$ documento vigente foi aprovado pelo Conselho Federal de Medicina em 2009 por meio da Resolução CFM n ${ }^{\circ} 1.931 / 09$. No capítulo V, que dispõe sobre a "Relação com pacientes e familiares", o código afirma que é vedado ao médico "desrespeitar o pudor de qualquer pessoa sob seus cuidados profissionais". O pudor é ainda, nessa enunciação contemporânea da medicina, atribuído ao paciente; ele continua a fazer parte da relação médico-paciente como uma exterioridade ao médico, a quem cabe respeitá-lo em "qualquer pessoa sob seus cuidados profissionais".

Nos Cadernos CREMESP - Ética em Ginecologia e Obstetrícia, a orientação ética, no que toca à relação médico-paciente, retoma o respeito ao pudor preconizado no código federal como "respeito à intimidade da paciente". No capítulo "Ética no exercício da Ginecologia e Obstetrícia", encontramos no interior da primeira seção, intitulada "A relação médico-paciente", no item "Atendimento aos direitos das pacientes", o sub-item "direito ao respeito", que cito:

Direito ao respeito: de forma bastante especial, o respeito à intimidade da paciente na esfera tocoginecológica é tópico de suma importância. Em razão disso, a presença de auxiliar de sala em consultórios é imperiosa. Nas demais situações, o respeito aos pacientes é parte integrante da conquista da cidadania. (Cadernos CREMESP, 2011, p. 83, grifo meu).

$\mathrm{O}$ "respeito à intimidade da paciente" justifica como "imperiosa" a presença de auxiliar ao lado do médico no momento da consulta ginecológica. A conduta recomendada é oposta à que vimos preconizada na enunciação de médicos franceses do século XIX "não pedir ajuda a outros, cuja presença é frequentemente mal tolerada"; a razão alegada nos dois momentos, no entanto, parece ser a mesma: o respeito ao "pudor" ou à "intimidade" da paciente. A inversão na conduta, por outro lado, sinaliza uma mudança nas condições de produção desse dizer.

Para entendermos as condições de produção dessa recomendação, remetemos ao fato de que ela distingue o exame tocoginecológico de outros exames clínicos: ela é própria da clínica tocoginecológica, na qual o médico examina os órgãos sexuais da mulher. Remetemos também ao seu modo de efetivação: na prática, a recomendação é cumprida por médicos homens, e não por médicas; as auxiliares, por sua vez, são sempre mulheres. Esses não-ditos no dizer da recomendação nos fazem compreender que ela diz respeito às relações de gênero, e ao fato de o exame tocoginecológico se dar sobre os órgãos sexuais da mulher. Essas questões, por sua vez, nos conduzem ao capítulo "Assédio sexual em Ginecologia e Obstetrícia" dos Cadernos.

Nesse capítulo, aprendemos que ginecologistas-obstetras "são o segmento mais denunciado por assédio sexual entre todas as especialidades" (Cadernos CREMESP, 2011, 
p. 249). É ao fato jurídico do assédio, portanto, que essa recomendação nos cadernos de ética está respondendo. Os Cadernos CREMESP trazem dados de assédio sexual na medicina da mulher. $\mathrm{O}$ assédio é qualificado como "uma forma de violência moral no contexto das relações de gênero, ao qual se associam os conceitos de honra e vergonha, ensejando processo de ressarcimento por dano moral" (Cadernos CREMESP, 2011, p. 259-60). Entretanto, ainda que seja qualificado como "uma forma de violência moral no contexto das relações de gênero", o assédio não é tratado relativamente à violência da conduta do médico assediador, mas como fruto de um "distúrbio de comunicação na relação ginecologista-paciente com queixas sexuais":

\begin{abstract}
A possibilidade mais terrível de distúrbio de comunicação na relação ginecologista-paciente com queixas sexuais ocorre quando a formação do médico é tão "mecânica" tecnicamente e tão machista culturalmente a ponto de confundir a necessidade de apoio e orientação emocionais da paciente com “desejo de intimidade" ou "insinuação erótica". Os aspectos psicossociais do ser mulher e sua sexualidade provavelmente não fizeram parte nem do curso de graduação, nem da Residência de Ginecologia e Obstetrícia, mas as pacientes não seguem essa lógica fragmentada. As pacientes são pessoas inteiras, que esperam que seus ginecologistas entendam de tudo que elas fazem com seus aparelhos reprodutores, até de amor! Várias das denúncias de assédio sexual envolvendo ginecologistas que chegam aos tribunais da Justiça Comum e do Cremesp contêm elementos referentes a este despreparo profissional. (Cadernos CREMESP, 2011, p. 262, grifo meu).
\end{abstract}

A partir da qualificação do assédio como violência de gênero, seria esperado que a qualificação da formação médica como "mecânica tecnicamente" e "machista culturalmente" fosse mobilizada para ressaltar a violência do assédio e sua relação com as práticas sociais divididas pela assimetria de gênero. Contudo, a violência do assédio é atenuada, ao ser explicada como fruto de uma "confusão" do médico em relação à "necessidade de apoio e orientação emocionais da paciente", que ele interpretaria equivocadamente como "desejo de intimidade" ou "insinuação erótica". As mulheres, enquanto "pacientes", são qualificadas como "pessoas inteiras, que esperam que seus ginecologistas entendam de tudo que elas fazem com seus aparelhos reprodutores, até de amor!". Diante da "integridade" da paciente-mulher, o "despreparo profissional" do médico silencia a integridade do médico enquanto sujeito.

A formação médica, segundo a enunciação dos Cadernos, não contempla "os aspectos psicossociais do ser mulher e sua sexualidade". Os aspectos psicossociais do ser homem e sua sexualidade, que dizem respeito ao médico, ficam silenciados. Assim como no século XIX francês, apenas a subjetividade da paciente, subsumida pela diferença de gênero, é considerada. A enunciação dos Cadernos perde de vista o fato de que, assim como a mulher paciente, o médico é um sujeito constituído "nas práticas sociais e por elas". Enquanto agente da prática médica, ele age "na e sob a determinação das formas históricas de existência" (HENRY, 1977, p. 23).

\title{
Os silêncios do pudor atribuído à mulher
}

Quando percorremos a palavra pudor ou sua equivalente pudeur na enunciação da medicina da mulher, seja no século XIX francês, seja na contemporaneidade brasileira, vemos que ela faz ecoar um discurso moral constituído na divisão social assimétrica de 
gênero, que a medicina reproduz e reforça. A reflexão e a prática médica são afetadas por essa exterioridade moral, que a palavra pudor materializa e permite deslizar para outras, como "intimidade".

Os efeitos do machismo na ciência e na prática médica devem ser pensados em relação à sexualidade do médico, a suas fantasias de poder e dominação. São elas que levam ao assédio, e não um "distúrbio de comunicação" entre médico e paciente. Quando um manual de ética médica, mesmo reconhecendo a "cultura machista" presente na formação do médico, explica o assédio sexual como fruto de uma "confusão" em relação às expectativas da paciente, é essa "cultura machista" que ele protege e faz significar.

Orlandi, em sua reflexão sobre o silêncio, caracteriza a censura como "o processo pelo qual se procura não deixar o sentido ser elaborado historicamente para ele não adquirir força identitária, realidade social, etc. (...) (ORLANDI, 1992, p. 176). Na enunciação dos Cadernos CREMESP, o silêncio constitutivo, que impede o questionamento da sexualidade e da subjetividade do médico, opera junto ao silêncio local uma política de interdições: "a censura estabelece um jogo de relações de força pelo qual ela configura, de forma localizada, o que, do dizível, não deve (não pode) ser dito quando o sujeito fala" (ORLANDI, 1992, p. 79). A palavra pudor e os ecos de sua significação em 'respeito à intimidade na mulher' trabalham impedindo tanto o movimento identitário da mulher quanto o movimento identitário do médico.

\section{O silêncio como ferramenta de interpretação}

Compreender o silêncio como fundador da significação leva a considerar na interpretação do dizer a política de impedimentos e interdições que faz parte do seu funcionamento, com os silêncios constitutivo e local. Por isso, essa concepção oferece uma ferramenta de leitura fundamental na formação crítica do sujeito. Ela se torna particularmente relevante em uma democracia frágil institucionalmente como a brasileira, e impreterível em tempos de ameaça à democracia como o que estamos vivendo. Vou lembrar aqui gestos de censura recentes.

Em 2017, a performance de Wagner Schwartz na mostra Panorama da Arte Brasileira do Museu de Arte Moderna de São Paulo, uma interpretação da obra "La bête", de Lygia Clark, foi interrompida após o linchamento virtual do artista. A censura, endossada por políticos e juristas conservadores ${ }^{4}$, teve como gatilho um vídeo divulgado nas redes sociais em que uma criança, que estava acompanhada pela mãe, tocava o pé do artista nu durante a performance. $\mathrm{O}$ artista foi acusado de pedofilia e sofreu uma investigação na Vara da Infância e da Juventude de São Paulo, na qual foi inocentado.

O nonsense de uma acusação de pedofilia a partir de um gesto espontâneo de uma criança interagindo em um espaço público de arte onde ela estava acompanhada da mãe só pode ser compreendido se consideramos a relação entre censura e arbitrariedade. $\mathrm{Na}$ mesma época, outra exposição foi censurada. A Queermuseu - cartografias da diferença na arte da brasileira, que tinha como temática a sexualidade humana em suas diferenças, foi cancelada pelo Santander Cultural de Porto Alegre após pressões de grupos organiza-

4 Para relembrar, ver, por exemplo, a reportagem do site G1 em que aparecem manifestações contrárias à performance e a resposta do museu. Disponível em: <https:/g1.globo.com/sao-paulo/noticia/interacao-decrianca-com-artista-nu-em-museu-de-sp-gera-polemica.ghtml.> Publicação em 28 set. 2017, atualização em 29 set. 2017, acesso em 01 maio 2018. 
dos. Mais uma vez, a decisão jurídica foi favorável à arte. Mas mesmo com a recomendação do Ministério Público Federal ${ }^{5}$, a exposição não foi reaberta.

Ao perguntar o que calava a recomendação de 'respeito à intimidade da paciente' nos Cadernos CREMESP, encontramos nos silêncios e implícitos de sua enunciação ecos da memória de sentidos das palavras pudor/pudeur fazendo significar na reflexão sobre a ética médica a reprodução da divisão social assimétrica de gênero. É preciso replicar o gesto e perguntar o que calam os gestos de censura que têm sido frequentes nos dois últimos anos no Brasil.

A arte questiona nossas certezas, tornando visível a possibilidade de outros modos de olhar e de estar na vida para além daqueles que vão sendo normalizados pelos discursos dominantes. Ela pode provocar tanto incômodo quanto alívio. Seu potencial transformador está em que ela nos interpela e nos interroga pela emoção. Por isso, gestos de censura à arte são comuns na história de governos autoritários.

Os espaços formais de educação também são comumente afetados pela censura em regimes autoritários. Assim como a arte, o pensamento crítico coloca em xeque nossas certezas. No Brasil, a partir de 2016, projetos de lei que cerceiam a prática de ensino foram postos em votação em câmaras municipais de todo o país e um projeto equivalente foi encaminhado ao Senado ${ }^{6}$. O movimento autointitulado Escola sem Partido busca transformar em lei da educação seis “deveres do professor”. O movimento afirma que esses "deveres” já existem, alegando que derivam da Constituição Federal do Brasil e da Convenção Americana sobre Direitos Humanos; o argumento, é claro, é falacioso, pois se esses deveres existissem de fato nessas instâncias, não haveria tamanho empenho para torná-los leis.

Os "deveres" propostos impedem o professor de manifestar posições políticas ou teóricas e de fomentar ações políticas na escola ${ }^{7}$; ao fazê-lo, ferem os direitos do professor e do aluno ao pensamento autônomo e ao exercício pleno da cidadania. Desse modo, o movimento que se diz "sem partido" está longe de ser neutro; ele fere a ética posta na Declaração Universal dos Direitos Humanos, adotada pelas Nações Unidas após a Segunda Guerra Mundial. A Declaração é um compromisso de promover "o advento de um mundo em que mulheres e homens gozem de liberdade de palavra, de crença e da liberdade de viverem a salvo do temor e da necessidade". É sempre bom lembrar o texto da Declaração:

(...) a Assembléia Geral proclama a presente Declaração Universal dos Direitos Humanos como o ideal comum a ser atingido por todos os povos e todas as nações, com o objetivo de que cada indivíduo e cada órgão da sociedade tendo sempre em mente esta Declaração, esforce-se, por meio do ensino e da educação, por promover o respeito a esses direitos e liberdades, e, pela adoção de medidas progressivas de caráter nacional e internacional, por assegurar o seu reconhecimento e a sua observância universais e efetivos, tanto entre os povos dos próprios Países-Membros quanto entre os povos dos territórios sob sua jurisdição ${ }^{8}$.

5 Para relembrar, ver, por exemplo, a reportagem do site G1. Disponível em: $<$ https://g1.globo.com/rs/riogrande-do-sul/noticia/mpf-recomenda-imediata-reabertura-da-exposicao-queermuseu-ao-santander-cultural.ghtml >. Publicação em 29 set. 2017, acesso em 01 maio 2018.

6 Para mais detalhes sobre os resultados das propostas no país, ver, por exemplo, a reportagem do Nexo, disponível em: < https://www.nexojornal.com.br/expresso/2017/09/05/O-que-aconteceu-com-as-propostasda-Escola-sem-Partido-pelo-Brasil>. Publicação em 05 set. 2017, acesso em 01 maio 2018.

7 Para conhecer o "programa" do Escola sem Partido, ver <https://www.programaescolasempartido.org/>. Acesso em: 01 maio 2018.

8 A Declaração está disponível, entre outros sites, no da UNICEF: <https://www.unicef.org/brazil/pt/resources_10133.htm>. Acesso em: 06 maio 2018, grifos meus. 


\section{Conexão Letras}

A "liberdade de palavra" é um princípio fundamental da Declaração, que o Escola sem Partido quer interditar ao professor. O compromisso do ensino e da educação deve ser a promoção do respeito aos direitos e liberdades afirmados na Declaração, que partem da universalidade do princípio de igualdade entre os sujeitos.

\section{É preciso conhecer os gestos de censura para não repeti-los}

Na ditadura militar, o projeto de "educação para a liberdade" de Paulo Freire levou ao seu exílio. Mais de cinquenta anos depois, constituído em Estado democrático de Direito, o Brasil precisa relembrar episódios como esse para não os repetir. Precisa também relembrar a necessidade de promover uma educação que, "desvestida da roupagem alienada e alienante, seja uma força de mudança e de libertação" (FREIRE, 1967, p. 36). A liberdade no projeto de educação de Paulo Freire combate a alienação e a domesticação do sujeito. Para educar para a liberdade, o professor precisa estar livre da arbitrariedade e da censura. A compreensão do silêncio contribui para uma educação que liberte e mobilize o pensamento e as ações dos alunos e professores na direção de um país que cumpra a igualdade de direitos afirmada na Declaração Universal dos Direitos Humanos. É a universalidade dos princípios da Declaração que deve constituir qualquer ética: seja na medicina, na arte, ou na escola.

\section{Referências}

ARNAUD-LESOT, S. Pratique médicale et pudeur féminine au XIXème siècle. Histoire des Sciences Médicales, v. 2, n. XXXVIII, 2004, p. 207-218.

COURTINE, J.-J. ; VIGARELLO, G. La physionomie de l'homme impudique. Communications, n. 46, 1987, p. 79-91.

DUCROT, O. Pressupostos e subentendidos: a hipótese de uma semântica linguística.

In: DUCROT, O. O dizer e o dito. Campinas: Pontes, 1987.

FREIRE, P. Educação como prática da liberdade. Rio de Janeiro: Civilização Brasileira, 1967.

. Pedagogia do oprimido. 17. ed. Rio de Janeiro: Paz e Terra, 1987.

HENRY, P. A ferramenta imperfeita: língua, sujeito e discurso. Campinas: Editora da Unicamp, 1992.

ORLANDI, E. P. As formas do silêncio no movimento dos sentidos. Campinas: Editora da Unicamp, 1992.

ROHDEN, F. Ginecologia, gênero e sexualidade na ciência do século XIX. Horizontes Antropológicos, Porto Alegre, ano 8, n. 17, junho de 2002, p. 101-125.

. Uma ciência da diferença: sexo e gênero na medicina da mulher. 2. ed. Rio de Janeiro: Editora Fiocruz, 2001. Antropologia \& Saúde collection. Disponível em: $<$ http://books.scielo.org/id/8m665/pdf/rohden-9788575413999.pdf $>$. Acesso em: 19 nov. 2016.

Recebido em: 11/05/2018 Aceito em: 28/05/2018 